\title{
Health-Promoting Lifestyle in Patients with and without Diabetes in
}

\section{Iran}

\author{
Hamid Vahedi, ${ }^{1}$ Ahamd Khosravi, ${ }^{2}$ Zakieh Sadeghi, ${ }^{3}$ Roqayeh Aliyari, ${ }^{4}$ Alihassan Shabankhamseh, ${ }^{5}$ \\ Maryam Mahdavian, ${ }^{6}$ Ehsan Binesh, ${ }^{7}$ and Mohammad Amiri ${ }^{8,}$ \\ ${ }^{1}$ Internist and Gastroenterologist, Shahroud University of Medical Sciences, Shahroud, IR Iran \\ ${ }^{2}$ Center for Health Related social and Behavioral Sciences Research, Shahroud University of Medical Sciences, Shahroud, IR Iran \\ ${ }^{3}$ Analytical Chemistry, Shahroud, IR Iran \\ ${ }^{4}$ Department of Biostatistics, Faculty of Medical Sciences, Tarbiat Modares University, Tehran, IR Iran \\ ${ }^{5}$ Management Specialist Assistant Professor in Deputy of Current Affairs (Moh \& Me) Ministry of Health and Medical Education, Tehran, IR Iran \\ ${ }^{6}$ Imam Hossein Hospital, Shahroud University of Medical Sciences, Shahroud, IR Iran \\ ${ }^{7}$ Department of Infection Disease, Imam Hossein Hospital, Shahroud University of Medical Sciences, Shahroud, IR Iran \\ ${ }^{8}$ Department of Public Health, School of Public Health, Shahroud University of Medical Sciences, Shahroud, IR Iran \\ "Corresponding author: Mohammad Amiri, Department of Public Health, School of Public Health, Shahroud University of Medical Sciences, Shahroud, IR Iran. Tel: \\ +98-2332374350, Fax: +98-2332335588, E-mail: m_amiri_71@yahoo.com
}

Received 2016 May 24; Revised 2016 August 02; Accepted 2016 September 16.

\begin{abstract}
Background: Diabetes is among the prevalent chronic non-communicable diseases, which in recent decades has dragged much attentions toward improving care of patients in Iran.

Objectives: The current study aimed to compare the health-promoting lifestyle of patients with and without diabetes.

Methods: In the current study, 150 patients with diabetes and 150 patients without diabetes referred to the Imam Hossein subspecialty Clinic in Shahroud in 2014 were enrolled. Data collection tools included a 52-item lifestyle questionnaire and a 22-item nutritional behavior and dietary habits questionnaire. Data were analyzed using ANOVA and conditional multiple logistic regression.

Results: The mean score of nutritional behavior in patients with and without diabetes were $20.9 \pm 3.9$ and $19.9 \pm 4.1$, respectively. Over $75 \%$ of the patients with diabetes had not passed the training course. The results of multivariate model showed the odds of having diabetes in people with obesity was 2.6 times more than that of the people with normal weight. Interpersonal relationship, stress management, physical activity and nutrition scores in patients with diabetes were significantly lower than those of the patients without diabetes $(\mathrm{P}<0.05)$. Negative relationship was observed between physical activity and diabetes (odds ratio $(\mathrm{OR})=$ 0.916; 95\% confidence interval $(\mathrm{CI})=0.850-0.987)$.

Conclusions: Patients with diabetes need more attention and care to manage diabetes to change their lifestyle to adjust with their conditions. Stress management, improved interpersonal relationships, physical activity and diet in this group can have a role to control the disease.
\end{abstract}

Keywords: Diabetes Mellitus, Knowledge, Attitude, Lifestyle

\section{Background}

With the epidemiological transition of diseases in recent decades, the prevalence of non-communicable diseases including diabetes is rising in the developing countries and in the Middle East(1). Diabetes is a chronic disease which inflicts short-term and long-term complications on the individual (2).

The studies in Iran report prevalence of diabetes in the general population $3.5 \%$ to $4.5 \%$ and in the population over 30 years even up to $14 \%$, and in all provinces its prevalence is higher in females than males (3-5). According to the report of deputy of health at Shahroud University of Medical Sciences, the prevalence of diabetes in the over 30 years rural population is $6.25 \%$.
Diabetes causes various complications related to some vital organs in body. In fact, diabetes is the most common cause of kidney failure, blindness, non-traumatic amputations and neuropathy $(6,7)$. Experts believe that the recent outbreak of type 2 diabetes is not characterized by changes in the genetic and ethnic characteristics of individuals in the community, but changes in the lifestyle of people and modernization of the society have the greatest impact on the increased incidence of diabetes (8). Lifestyle is a highly important factor related to development and control of diabetes in patients (9). Lifestyle includes behaviors such as eating habits, sleep and rest, physical activity and exercise, weight control, smoking and alcohol use, immunization against diseases, coping with stress and the ability to use family and community support; optimum 
lifestyle can prevent many diseases and is a way to improve the health, quality of life and coping with stress $(10,11)$. Physical inactivity is associated with an increased prevalence of diabetes and metabolic syndrome (12). Regular physical activity is lower in females than in males, and its amount also decreases with aging. Low level of activity is related to many diseases and conditions such as loss of muscle strength and flexibility, weight gain and obesity, impotence, premature mortality (caused by cardiovascular diseases) and non-insulin dependent diabetes (13).

A study in North of Iran indicates a positive effect of lifestyle on type 2 diabetes (14). Marker et al. (15) believe that patients with diabetes have an inappropriate lifestyle. de Groot et al. (16) showed that patients with diabetes had incorrect lifestyles, inappropriate diet and no exercise. Results of researches in Iran showed that selfmanagement interventions, increasing physical activity, improving diet, family-centered empowerment and training programs were effective in improving lifestyle and diabetes control $(17,18)$. Another study found that $95.5 \%$ of patients had intermediate-risk lifestyle (19).

Lifestyle interventions such as physical activity, proper diet, self-care, awareness raising and people empowerment and the quality of life improvement play roles in decreasing the morbidity and mortality associated with diabetes $(20,21)$.

Since diabetes is a chronic disease which imposes heavy costs on the healthcare system, awareness of the relevant factors in different populations is necessary and makes it possible to plan for feasible preventive and therapeutic measures $(22,23)$. According to the above mentioned relationship of lifestyle and control of diabetes complications $(17,18)$, and since there were no studies on the relationship between individual health aspects of lifestyle and diabetes in Shahroud, the current study was conducted.

\section{Objectives}

The study aimed to compare the health related lifestyle between the patients with and without diabetes in Shahroud, Northeast of Iran.

\section{Methods}

In the current study, 150 patients with diabetes who referred to diabetes clinic of Imam Hossein hospital in Shahroud were selected and each patient was matched for age with a patient without diabetes selected from specific clinics. The controls were selected from the same age range with five years tolerance. Simple random sampling method was employed to select the subjects. Out of the 840 registered patients with diabetes (prevalent cases) in the diabetes clinic, 170 patients were selected according to their medical records. Of these selected patients, finally 150 patients were interviewed and completed the questionnaire. For every case, an age matched patient without diabetes was selected form the admitted patients in imam Hossein hospital as control. The controls were selected from orthopedics, urology, ear, nose and throat (ENT), cardiology, dermatology, internal medicine, and surgery clinics.

\subsection{Inclusion and Exclusion Criteria}

The patients with active medical records of diabetes were selected for the case group. Active medical record was defined as a patient with diabetes that had at least one visit to diabetes clinic in the past year. The protocol of this study was approved by the ethical board review of Shahroud University of Medical Sciences (No. 9209). Subjects signed a written informed consent after explaining the goals to them.

Blood pressure was measured using a mercury sphygmomanometer on the right arm, in sitting position after five minutes rest, by a trained nurse. Blood pressure was measured twice with an interval of three minutes. Hypertension is defined as systolic blood pressure $\geq 140$ and/or diastolic blood pressure $\geq 90 \mathrm{mmHg}$ or current use of antihypertensive medication (24). Smoking was defined as smoking one or more cigarette per day. The history of cardiovascular and kidney diseases and stroke was measured interviewing and assessing the patients' medical records. Body-weight was measured to the nearest $0.05 \mathrm{~kg}$ by a digital scale. Body height was measured by means of a tapeline to the nearest $0.001 \mathrm{~m}$. After measuring the weight and height of patients, the body mass index (BMI) was calculated by dividing weight (in kilograms) on the square of height (in meters). Overweight was defined as a BMI greater or equal to $25 \mathrm{~kg} / \mathrm{m}^{2}$, and obesity was defined as a $\mathrm{BMI} \geq 30 \mathrm{~kg} / \mathrm{m}^{2}$ (25).

The health-promoting lifestyle questionnaire consists of 52 items in six areas of nutrition ( 8 items), physical activity ( 8 items), health responsibility (13 items), stress management ( 5 items), interpersonal relationships ( 8 items) and spiritual growth (10 items). Reliability and validity of this inventory is confirmed in Iran (26) and its reliability was reported 0.82. A researcher-made questionnaire was used, which included 34 items that sought awareness and attitudes of patients about diabetes; the reliability of the questionnaire was 0.71 .

The independent variables in the study were healthpromoting lifestyle (with six dimensions), knowledge and attitude about diabetes, and questions about history of 
high blood pressure, stroke, cardiovascular diseases and kidney diseases and demographic variables (gender, education level and marital status). Four valid questions about knowledge and four valid questions about attitude toward diabetes were used. These questions were designed according to the surveillance system protocols (27). The total score for knowledge ranged between 0-8 and for attitude was 1 to 20. The score greater and equal to 7 and 15 respectively showed the desirable knowledge and positive attitude.

The collected data were analyzed using SPSS ver. 16. First, by contingency tables, distribution of explanatory variables (independent) was divided into two groups. According to the matching of cases and controls on age, conditional logistic regression model was used. In this model, the effects of life-style, smoking, knowledge, attitude, hypertension, BMI, educations, marital status, along with matched variable of age were used to prevent bias in casecontrol due to the matching.

\section{Results}

In the current study, 150 patients with diabetes and 150 patients without diabetes participated; $27.3 \%$ were male, $10.7 \%$ were smokers and $31.3 \%$ had obesity in the group with diabetes and in the group without diabetes 39.3\% were male, $10.7 \%$ were smokers and $13.3 \%$ had obesity. The mean duration of involvement with diabetes was $7.59 \pm 5.97$ years and the mean of age was $46.6 \pm 16.4$ years.

Table 1 presents the univariate comparison of some baseline variables between diabetic and non-diabetic groups. As indicated, there was a significant difference between the two groups in terms of gender, marital status, education levels, hypertension, history of cardiovascular disease, history of kidney disease, history of stroke, daily physical activities, training experience in the field of diabetes, BMI, knowledge and attitude $(\mathrm{P}<0.05)$.

Comparison of health-promoting lifestyle subscale scores between the patients with and without diabetes is presented in Table 2. As indicated, the mean score of interpersonal relations, stress management, physical activity and nutrition scores in patients with diabetes are lower than that of those without diabetes $(\mathrm{P}<0.05)$.

In a multiple logistic model, independent variables such as gender, marital status, education levels, history of hypertension, cardiovascular disease and kidney disease, training experience in the field of diabetes, BMI, knowledge, attitude and dimensions of health-promoting lifestyle were assessed. The odds ratio for diabetes in people who had completely positive attitude in the field of diabetes was 7.6 times higher than those of the ones with a negative attitude. Chance of having diabetes for subjects with obesity was 2.6 times higher than those of the ones with normal weight. The odds of having diabetes for those who had a relatively positive attitude about diabetes were 0.13 times higher than those of the ones with positive attitudes toward diabetes. Also the model showed negative relationship between physical activity and diabetes $(\mathrm{P}=$ 0.021) (Table 3).

\section{Discussion}

Based on the findings of the current study (in terms of health-promoting lifestyle subscales) stress management, physical activity, nutrition and interpersonal relationship scores in patients with diabetes are significantly lower than those of patients without diabetes. Another study showed that improving lifestyle reduces the incidence of diabetes (28). Therefore, with respects to positive impact of life-style on the control of complications of diabetes, it is necessary to pay more attention to this issue.

Most of the participants of this study were females (gender ratio $=2$ ), which was consistent with the findings of some studies $(17,29-31)$ but was inconsistent with the results of other studies $(14,32,33)$. In the current study, design and method used to select patients from a subspecialty clinic showed that females had more visits and received care services.

The proportion of married people was more prevalent in patients with diabetes than the ones without diabetes, which was consistent with the results of some other studies $(4,30,31,34)$. In univariate analysis a significant relationship was observed between marital statuses in the two groups, but in the multivariate model, the marital status was not related to diabetes condition.

Education level based on years of education in patients with diabetes was lower than that of patients without diabetes; a significant difference was observed between the two groups in terms of education levels. It was in line with the results of Kheirjoo et al. and Shojaeizadeh et al. (14,34), but not with those of some other studies $(14,31)$. Probably, higher education makes the importance of health clearer to people and encourages them to take health-promoting measures.

Obesity in patients with diabetes was more than ones without diabetes and the difference was statistically significant, which was consistent with the results of Shojaeizadeh et al. (14).

Mean level of knowledge in patients with diabetes was higher than that of the patients without diabetes, which was consistent with the results of Shamsi et al., and Hosseini et al. $(4,17)$, but inconsistent with the results of Goodarzi et al. and Bayat et al. $(30,31)$. 
Table 2. The Comparison of Health-Promoting Lifestyle Between the Case and Control Groups

\begin{tabular}{lrr}
\hline Health-Promoting Lifestyle Subscales & Patients With Diabetes & Patients Without Diabetes \\
\hline Spiritual growth & $27.3 \pm 6.15$ & $28.05 \pm 5.46$ \\
Health responsibility & $33.68 \pm 7.14$ & $33.42 \pm 7.40$ \\
\hline Interpersonal relations & $20.66 \pm 5.17$ & 0.263 \\
Stress management & $11.13 \pm 2.84$ & $22.81 \pm 4.76$ \\
Physical activity & $10.08 \pm 3.57$ & $12.19 \pm 2.98$ \\
Nutritional habits & $19.92 \pm 4.12$ & 0.001 \\
\hline
\end{tabular}

Table 3. The Multivariate Association Between Some Variables in the Two Groups by Forward Stepwise Logistic Regression Model ${ }^{\mathrm{a}}$

\begin{tabular}{|c|c|c|c|c|c|}
\hline Variables & $\beta$ & PValue & OR & \multicolumn{2}{|c|}{ 95\% CI for OR } \\
\hline Overweight & -0.132 & 0.754 & 0.876 & 0.385 & 1.998 \\
\hline Normal & -0.940 & 0.014 & 0.391 & 0.185 & 0.827 \\
\hline Physical activity & -0.088 & 0.021 & 0.916 & 0.850 & 0.987 \\
\hline \multicolumn{6}{|c|}{ Attitude (reference group: positive) } \\
\hline Fairly positive & -2.035 & 0.000 & 0.131 & 0.052 & 0.331 \\
\hline Constant & -2.431 & 0.003 & 0.088 & & \\
\hline
\end{tabular}

Abbreviations: OR, odds ratio; $\mathrm{CI}$, confidence interval.

${ }^{a}$ Independent variables: gender, marital status, education levels, history of hypertension, cardiovascular disease and kidney disease, training experience in the field of diabetes, body mass index, knowledge, attitude and dimensions of health-promoting lifestyle.

The score of positive attitude towards diabetes control was higher among people with diabetes than people without diabetes. Results of Hosseini et al. (17) also showed higher scores of attitude in cases than controls. In a study by Goodarzi et al. (30) the attitude of the participants was also positive, which was consistent with the current study results. Shamsi et al. (4) pointed to lower scores of patients with diabetes compared to those of the controls, which was not consistent with the current study results. One possible reason for the positive attitude of patients with diabetes toward diabetes control was the hardship and pains experienced by such patients during their disease and this makes them aware of its serious consequences.

The mean scores of dimensions of health-promoting lifestyle in the accountability aspect and spiritual growth and self-actualization were not significantly different in the two groups, which were not consistent with results of Kheirjoo et al., and Asadnia et al. $(34,35)$.

The mean score of health-promoting lifestyle in physical activities and nutrition dimensions in the two groups had significant differences, which was consistent with the results of some studies $(14,31,34,35)$. Patients with diabetes are recommended to be more active and have proper diet to improve their health-promoting lifestyle.

The mean score of health-promoting lifestyle in interpersonal relationships dimension in the two groups showed no significant difference, which was consistent with the results of Kheirjoo et al. and Asadnia et al. $(34,35)$.

The mean score of health-promoting lifestyle in stress management dimension in the two groups showed significant differences, which was consistent with the results of other studies $(14,35)$ but inconsistent with results of Kheirjoo et al. (34). Perhaps stress management and selfmanagement training measures could help to manage stress and control the disease in patients with diabetes.

However, age adjustment of the two study groups can improve the statistical efficiency. Hospital based selection of controls can inflate the study estimation because it can be different from normal population.

\subsection{Conclusion}

Patients with diabetes need more attentions and care to manage diabetes and need interventions to change the lifestyle to adjust with their conditions. Stress management, improved interpersonal relationships, physical activity and diet in this group can have a role to control the disease.

\section{Footnote}

Funding/Support: The present work was supported by Shahroud University of Medical Sciences (project No: 9209). 


\section{References}

1. Khoja T, Farid S. Family Health Surey: Principle report. Riyadh; 2000.

2. Mahan LK, Escott-Stump S. Krause's Food, Nutrition, \& Diet Therapy. 2000.

3. Baghiani MM, Afkhami AM, Mazloumi S, Saaidizadeh M. Quality of life in diabetes type II patients in Yazd.J Shahid Sadoughi Uni Med Sci Health Serv. 2007;14(4):49-54.

4. Shamsi M, Sharifirad G, Kachoue A, Hassanzadeh A. The effect of walking educational program on knowledge, attitude, performance, and blood sugar in women with type II diabetes. J Birjand Uni Med Sci. 2010;17(3):170-9.

5. Azizi F, Larijani B, Hossien Panah F. Endocrine Disorders. Tehran, Iran: University of Shahid Beheshty Publication; 2006.

6. Centers for Disease C. Blindness caused by diabetes-Massachusetts, 1987-1994. MMWR Morb Mortal Wkly Rep. 1996;45(43):937-41. [PubMed: 8927019].

7. Barr EL, Boyko EJ, Zimmet PZ, Wolfe R, Tonkin AM, Shaw JE. Continuous relationships between non-diabetic hyperglycaemia and both cardiovascular disease and all-cause mortality: the Australian Diabetes, Obesity, and Lifestyle (AusDiab) study. Diabetologia. 2009;52(3):415-24. doi:10.1007/s00125-008-1246-y. [PubMed: 19130039].

8. Joshi S, Shrestha S. Diabetes mellitus: a review of its associations with different environmental factors. Kathmandu Uni Med J. 2010;8(1):10915. doi: 10.3126/kumj.v8i1.3233.

9. Kotsanos JG, Vignati L, Huster W, Andrejasich C, Boggs MB, Jacobson AM. Health-related quality-of-life results from multinational clinical trials of insulin lispro: assessing benefits of a new diabetes therapy. Diabetes Care. 1997;20(6):948-58. doi: 10.2337/diacare.20.6.948.

10. Baroogh N, Teimouri F, Saffari M, Sadeh SH, Mehran A. Hypertension and lifestyle in 24-65 year old people in Qazvin Kosar region in 2007. Pajoohandeh J. 2010;15(5):193-8.

11. Monahan F, Sands J, Marek J, Neighbors M, Phipps W. Medical-surgical nursing: health and illness perspectives. Philadelphia: Mosby; 2002.

12. Church TS, Cheng YJ, Earnest CP, Barlow CE, Gibbons LW, Priest EL, et al. Exercise capacity and body composition as predictors of mortality among men with diabetes. Diabetes Care. 2004;27(1):83-8. [PubMed: 14693971].

13. Allen NA. Social cognitive theory in diabetes exercise research: an integrative literature review. Diabetes Educ. 2004;30(5):805-19. [PubMed: 15510532]

14. Shojaeizadeh D, Estebsari F, Azam K, Batebi A, Mostafaei D. Comparison of Diabetes Type II Patients Life Style Effective Factors With That of Healthy People. J Shahid Sadoughi Uni Med Sci. 2008;16(2):71-9.

15. Marker F, Craren J, Roding E. Relationship of self-sfficyand binging to adherenence to diabetes regimen among adolescence. Diabetes care EurJ Public Health. 2012;45(1):90.

16. de Groot M, Doyle T, Kushnick M, Shubrook J, Merrill J, Rabideau E, et al. Can lifestyle interventions do more than reduce diabetes risk? Treating depression in adults with type 2 diabetes with exercise and cognitive behavioral therapy. Curr Diab Rep. 2012;12(2):157-66. doi: 10.1007/s11892-012-0261-z. [PubMed: 22350739].

17. Hosseini F, Farshidi H, Aghamolaei T, Madani A, Ghanbarnejad A. The Impact of an Educational Intervention Based on Precede-Proceed Model on Lifestyle Changes among Hypertension Patients. Iran J Health Edu Health Promot. 2014;2(1):17-27.

18. Mahmmodirad G, Mohali F, Alhani F. Effect of Family-Centered Empowerment Model on The Lifestyle of Patients with Hypertension. Med-Surg NurJ. 2013;2(3-4):128-36.

19. Mohammadi Zeydi E, Heidar Nia A, Haji Zadeh E. The study of cardiovascular patient's lifestyle. Daneshvar. 2006;61(13):49-56.
20. Nicolucci A, Balducci S, Cardelli P, Cavallo S, Fallucca S, Bazuro A, et al. Relationship of exercise volume to improvements of quality of life with supervised exercise training in patients with type 2 diabetes in a randomised controlled trial: the Italian Diabetes and Exercise Study (IDES). Diabetologia. 2012;55(3):579-88. doi: 10.1007/s00125-011-2425-9. [PubMed: 22234648].

21. Williams GC, McGregor HA, Zeldman A, Freedman ZR, Deci EL. Testing a self-determination theory process model for promoting glycemic control through diabetes self-management. Health Psychol. 2004;23(1):58-66. doi: 10.1037/0278-6133.23.1.58. [PubMed:14756604].

22. Azizi FNL. Study of the Prevalence of Diabetes and Impaired Glucose Tolerance in rural Areas of Tehran Province. Hakim. 2001;4(2):92-9.

23. Mansoori F, Namdaritabar H, Shahrezaee A, Rezaei R, Alikhani A, Montazer MI. Diabetes Mellitus in Over-Thirty-Year-Old Individuals in Kermanshah Province (2002). J Kermanshah Uni Med Sci. 2004;8(2):57-68.

24. Chobanian AV, Bakris GL, Black HR, Cushman WC, Green LA, Izzo JL, et al. Seventh report of the Joint National Committee on Prevention, Detection, Evaluation, and Treatment of High Blood Pressure. Hypertension. 2003;42(6):1206-52. doi: 10.1161/01.HYP.0000107251.49515.c2. [PubMed: 14656957].

25. Khosravi A, Emamian MH, Shariati M, Hashemi H, Fotouhi A. The prevalence of pre-hypertension and hypertension in an Iranian urban population. High Blood Press Cardiovasc Prev. 2014;21(2):127-35. doi: 10.1007/s40292-013-0035-y. [PubMed: 24272061].

26. Rafatti M, Ghotbi M, Ahmadniya $H$. Fundumental of prevention and survielance of disease. Non-communicable disease surveilance system. Iran: Baghe Ketab publication; 2008.

27. Zeidi IM, Hajiagha AP, Zeidi BM. Reliability and validity of Persian version of the health-promoting lifestyle profile. J Mazandaran Uni Med Sci. 2012;22:103-13.

28. Tuomilehto J, Lindstrom J, Eriksson JG, Valle TT, Hamalainen $\mathrm{H}$, Ilanne-Parikka $\mathrm{P}$, et al. Prevention of type 2 diabetes mellitus by changes in lifestyle among subjects with impaired glucose tolerance. $N$ Engl J Med. 2001;344(18):1343-50. doi: 10.1056/NEJM200105033441801. [PubMed: 11333990].

29. Javadi A, Javadi M, Sarvghadi F. KAP in diabetes patients: case of Buali Sina Center, Qazvin Province. J Birjand Uni Med Sci. 2004;11(3):46-51.

30. Goodarzi M, Ebrahimzadeh I, Rabi A, Saedipoor B, Jafarabadi MA. Study of relation between knowledge, attitude, practice and self efficacy of patients with type 2 diabetes in Karaj Iran. Iran J Diabetes Lipid Disord. 2012;11(3):269-81.

31. Bayat F, Shojaeizadeh D, Hossaini SM, Sadeghi R. Effectiveness of Educational Program on Lifestyle Modification Among Type2 Diabetic Patients. Health System Res J. 2012;8(7):1235-44.

32. Nasrabadi T, Goodarzi Zadeh N, Shahrjerdi A, Hamta A. The Effect of Education on Life Style Among Patients Suffering from Ischemic Heart Disease. Mazandaran Uni Med Sci. 2010;20(79):72-9.

33. Rezaei N, Tahbaz F, Kimiagar M, Alavi Majd H. Effect of Nutrition Education on Biochemical indices, Nutritional Status, Knowledge, Attitude and Practice in type 1 Diabetes Mellitus. Iran J Diabetes Metabolism. 2006;5(3):244-56.

34. Kheirjoo E, Jomehri F, Ahadi H, Manisefat FF. Comparison of Health Promoting Lifestyle of Female Rheumatoid Arthritis Patients with Healthy Women and It's Relationship with Demographic Factors. J Knowledge Res Applied Psychol. 2013;13(4):61-70.

35. Asadnia S, Issazadeghan A, Ansari B. Evaluation of the Effectiveness of Cognitive Behavioral Therapy on Decreasing Depression Levels And Improving The Lifestyle Of Patients with Type 2 Diabetes. Urmia Uni Med Sci. 2013;24(10):812-22. 
Table 1. The Univariate Comparison of Some Baseline Variables Between the Case and Control Groups

\begin{tabular}{|c|c|c|c|}
\hline Variables & Patients With Diabetics & Patients Without Diabetes & PValue \\
\hline Food habits & $6.63 \pm 1.83$ & $7.03 \pm 1.57$ & 0.040 \\
\hline \multicolumn{3}{|l|}{ Gender } & \multirow{3}{*}{0.027} \\
\hline Male & $41(27.3)$ & $59(39.3)$ & \\
\hline Female & $109(72.7)$ & $91(60.7)$ & \\
\hline \multicolumn{3}{|l|}{ Marital status } & \multirow{3}{*}{$<0.0001$} \\
\hline Married & $136(90.7)$ & $110(73.3)$ & \\
\hline Single & $14(9.3)$ & $40(26.7)$ & \\
\hline \multicolumn{3}{|l|}{ Years of education } & \multirow{4}{*}{$<0.0001$} \\
\hline Illiterate & $64(42.7)$ & $20(13.3)$ & \\
\hline$<12$ yrs. & $60(40)$ & $64(42.7)$ & \\
\hline$\geq 12$ yrs. & $26(17.3)$ & $66(44.0)$ & \\
\hline \multicolumn{3}{|l|}{ Smoking } & \multirow{3}{*}{0.574} \\
\hline Smoker & $16(10.7)$ & $16(10.7)$ & \\
\hline Nonsmoker & $134(89.3)$ & $134(89.3)$ & \\
\hline \multicolumn{3}{|l|}{ Hypertension } & \multirow{3}{*}{0.001} \\
\hline Yes & $81(54.0)$ & $25(16.7)$ & \\
\hline No & $69(46.0)$ & $125(83.3)$ & \\
\hline \multicolumn{3}{|c|}{ History of cardiovascular disease } & \multirow{3}{*}{0.001} \\
\hline Yes & $44(29.3)$ & $14(9.3)$ & \\
\hline No & $106(70.7)$ & $136(90.7)$ & \\
\hline \multicolumn{3}{|c|}{ History of kidney disease } & \multirow{3}{*}{0.010} \\
\hline Yes & $32(21.3)$ & $15(10.0)$ & \\
\hline No & $118(78.7)$ & $135(90.0)$ & \\
\hline \multicolumn{3}{|l|}{ History of stroke } & \multirow{3}{*}{0.598} \\
\hline Yes & $9(6.0)$ & $6(4.0)$ & \\
\hline No & $141(94.0)$ & $144(96.0)$ & \\
\hline \multicolumn{3}{|c|}{ Daily physical activities } & \multirow{3}{*}{0.004} \\
\hline Yes & $60(40.0)$ & $86(57.3)$ & \\
\hline No & $90(60.0)$ & $64(42.7)$ & \\
\hline \multicolumn{3}{|c|}{ Training experience in the field of diabetes } & \multirow{3}{*}{0.028} \\
\hline Yes & $37(24.7)$ & $21(14.0)$ & \\
\hline No & $113(75.3)$ & $129(86.0)$ & \\
\hline \multicolumn{3}{|l|}{ BMI $^{\mathbf{a}}$} & \multirow{4}{*}{0.001} \\
\hline Normal & $45(30.0)$ & $65(43.3)$ & \\
\hline Overweight & $58(38.7)$ & $65(43.3)$ & \\
\hline Obese & $47(31.3)$ & $20(13.3)$ & \\
\hline \multicolumn{3}{|l|}{ Knowledge } & \multirow{3}{*}{0.003} \\
\hline Desirable & $100(66.7)$ & $76(50.7)$ & \\
\hline Undesirable & $50(33.3)$ & $74(49.3)$ & \\
\hline \multicolumn{3}{|l|}{ Attitude } & \multirow{3}{*}{0.001} \\
\hline Positive & $137(91.3)$ & $109(72.7)$ & \\
\hline Fairly positive & $13(8.7)$ & $41(27.7)$ & \\
\hline
\end{tabular}

${ }^{\mathrm{a}}$ BMI, body mass index. 